Session 2642

\title{
Integrated Product Development: Linking Business and Engineering Disciplines in the Classroom
}

\author{
Joseph A. Heim, Gary M. Erickson \\ University of Washington
}

Shorter product life cycles, increasing product variety, and customer demand for low cost and higher quality is driving manufacturing organizations to integrate the production process with upstream design activities and downstream marketing functions. Furthermore, there is a strong relationship between the time taken by a company to introduce new products to the marketplace, and the financial success to be enjoyed by that product over its marketable life time. ${ }^{1}$

In this paper, we discuss the development and delivery of a graduate course that examines many of the management, teaming, technology and economic challenges that must be addressed by firms that wish to remain competitive. The course focuses on the methodologies, tools, and structures needed for successful new product development efforts with a combination of lecture, student team product development projects and business community participation.

\section{Integrated Product Development}

Manufacturers have begun to realize that the product development strategies and organizational structures that have worked so well since the 1940s, are no longer appropriate for the circumstances in which they find themselves today. Revolutionary changes in customer expectations accompanied by intensifying international competition demand that similarly disruptive changes must occur in the manner in which new products are conceived, produced and delivered to the customer. Intellectually deciding what products the customer will purchase will no longer suffice.

One of the most profound challenges facing product manufacturers is the shortening of product life cycles. Customers have a more short-term, fashion-like attitude towards many products they purchase; they have no patience for products which do not meet their quality expectations nor have they any interest in good that do not fit their requirements for performance and features. In this environment, the producer must be able to understand the needs of the customer and respond with goods and services that delight the customer, that deliver a competitive suite of functions and desired performance at an attractive price and in a timely mannerwhen the customer wants them. ${ }^{2}$

Such changes are forcing organizations to substantially increase the involvement of customers in product development, and they are reexamining the critical relationships within the organization that influences how long it takes to create new products and bring them to market. Engineers must be able to help articulate the kinds of market intelligence they need to design and produce competitive products. And the people responsible for the marketing and financial aspects of product development must learn about the possibilities presented by alternative product and process technologies. They must also, however, understand the limitations and operational constraints imposed by current investments in equipment, machinery, and production facilities. 
Manufacturers must transform traditional product development procedures - characterized as organizationally-centered, low risk, sequential, one step at a time processes - into collections of concurrent activities, organized by multi-disciplinary teams that are intensively customer-focused. In this concurrent process model, the participants actively collaborate to reduce risks and improve the product development process by examining the downstream engineering and production consequences of early design and marketing decisions. ${ }^{3}$ You can see the differences in the two approaches to product development compared in Figure 1.

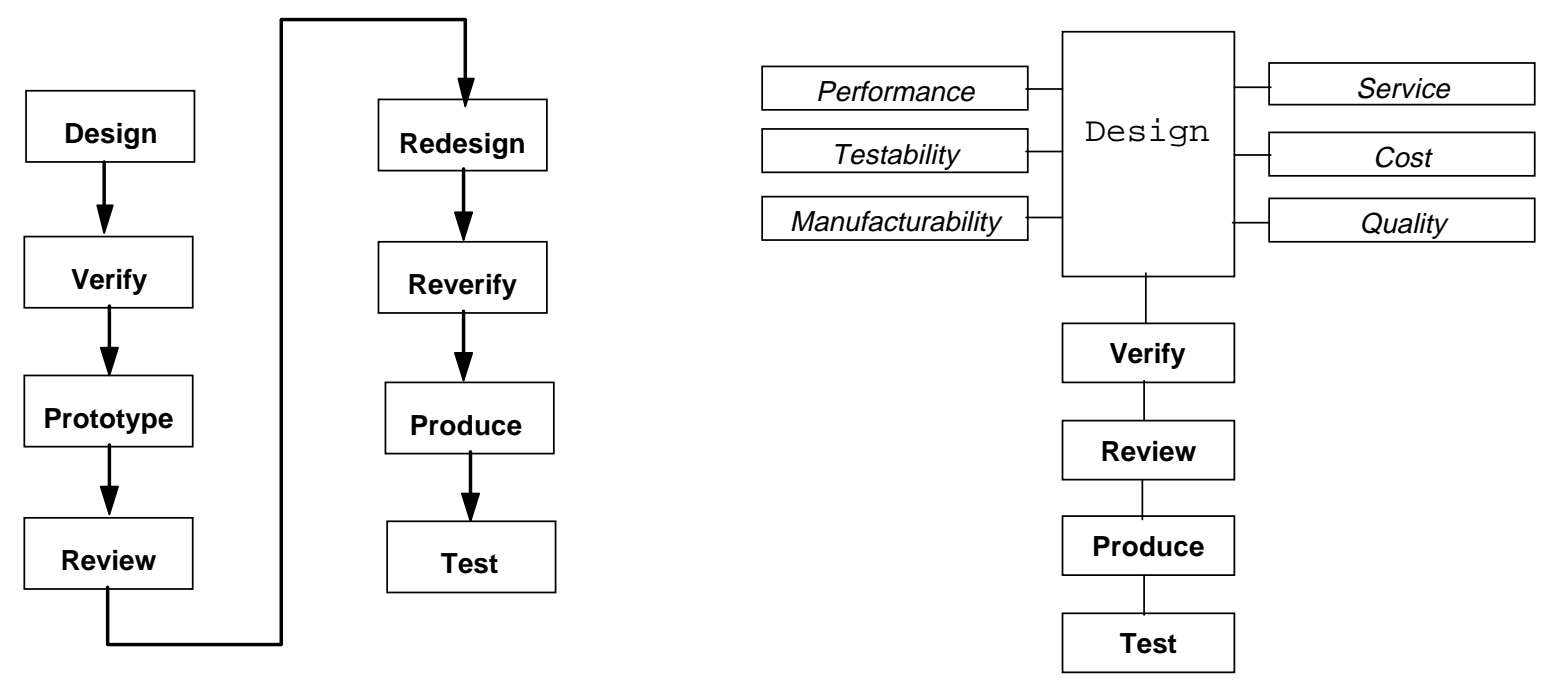

Sequential Activities Product Development

Concurrent Activities Product Development

FIGURE 1. The traditional sequential product development process compared to a concurrent product development process model. ${ }^{4}$

For most firms, these changes are profound challenges requiring a major metamorphosis in the way they develop new products. There are many opportunities for technology, properly used, to support this new mode of product development, but the structural and cultural changes in the organization can not be fully resolved by technology alone.

\section{Teaching Integrated Product Development}

Just as manufacturing organizations are realizing the need to change the way they develop new products, so must engineering and management education break free from existing ways of preparing students. The traditional educational experience offers students bits and pieces of specialized material, but little in the way of synthesis. For example, marketing departments of business schools teach new product development courses that offer great detail about marketing research requirements but provide little if anything about design and manufacturing aspects. Existing educational approaches are especially inadequate as they relate to product development, since the educational needs in this area extend beyond the boundaries of traditionally separate disciplines.

Courses, in fact entire programs, that focus on the importance of treating the product realization process as an integrated system are being developed at universities throughout the United States and Europe. ${ }^{\mathbf{5}}$ Most schools have been motivated by the "voice of the customer" - the companies hiring their graduate business and engineering students. The companies tell the universities what they need, and the universities work very hard to 
provide properly prepared engineers and managers. Industry recognizes that if they expect to compete in a much faster and more competitive environment, they must have appropriately prepared employees. They want their new employees not only intellectually conversant with the challenges confronting the companies, but also prepared to respond appropriately.

\section{Course Structure and Organization}

At the University of Washington, the Integrated Product Development course is open to both MBA and graduate engineering students. We try to enroll an equal number of engineering and business students in the class, since product development project teams need the talents of both groups.

The material presented throughout the quarter focuses on the three primary issues: the tools and technologies available to IPD teams; the organizational and cultural context in which IPD is most effective; and the importance of considering the entire product life cycle when developing new products.

\section{Selection and Use of Appropriate Tools and Technologies}

A wide variety of tools and technologies are available to product developers. One objective of the course is demonstrate how the traditional tools and methodologies of engineering and business can become competitive resources when used to collaboratively support product development team efforts. Our first challenge, then, is to help the students understand how to integrate the skills and tools they have already acquired in their individual disciplines. Limited class time (the University of Washington is on a 10-week quarter system) and the broad range of subjects we examine in the course means that we try not to introduce materials that would be new to all of the students in the class. But we know that some of the subjects discussed will be new for some students but a review for others.

\section{Organizational Aspects of Product Development}

Much of the difficulty associated with the rapid development of new products concerns communication and coordination among the many functional groups involved throughout the product development cycle. Although technology can lessen the severity of coordination and communication problems, substantive improvements in product development efficiency are likely to require cultural changes within the organization and reexamination of relationships among the manufacturer, its customers, and its suppliers. A substantial component of the IPD course addresses the problems of integrating human activities across such diverse disciplines as finance, marketing, engineering design and production, and distribution. The students learn that successful product development teams rely on the experience and technical expertise of appropriate members, but always examines the consequences of emergent dependencies and interactions before they become impediments to timely completion of the product development effort.

\section{Understanding Product Life Cycles}

Radically different products, products based on incremental improvements, and "platform" products, offer opportunities and risks that should be evaluated in the context of each organization. Another set of issues that engineers as well as business students must confront are the full life cycle environmental consequences of product design. ${ }^{6}$ Particular emphasis is placed on the importance of time-to-market and considering opportunities to increase market share by strategic vendor relationships as well as looking outside the organization for special talents or expertise. Case studies are used to examine the complexity of these problems and the contemporary approaches taken by companies. 


\section{Operational Issues}

In teaching the methodologies, tools, and structures needed to successfully develop new products, we combine lectures, case analyses, student team product development projects and business community participation. Our objective is to expose students to the fundamentals of IPD and illustrate the difficulty and practice needed to complete product development projects within time and budget constraints.

The three primary areas of focus in the course obviously cut broadly across disciplines. The authors are personally able to provide sufficient intellectual and practical guidance in matters of business and engineering. However, the third aspect of product development, what might be termed the "aesthetic" considerations of product development, has been provided by the professional Industrial Design community in Seattle.

\section{Product Development Project Teams}

Students are assigned to teams by the faculty in an effort to invest the teams with the skills we know they will need to complete their projects successfully. An equal number of students in the class come from the School of Business MBA program and engineers pursuing a graduate degree in the College of Engineering. Of course, the students have discipline specializations, such as finance or mechanical engineering. Trying to balance the sub-disciplines in each team is, in general, not necessary, since the skill set needed by the teams derive from the fundamentals taught in the respective schools.

Each team is paired with an Industry Mentor, an Industrial Design consultancy or individual that provides guidance and assistance in matters of human factors, materials selection, engineering prototype construction and usability. The students interact with the Mentors throughout the term. The degree of involvement varies widely and appears to depend on the dynamics of the teams, the Industrial Designer's availability and interest in the type of product the team is developing.

\section{Team Teaching}

Each of the authors had previously team-taught classes in which the instructors divided responsibilities for the lectures, but only the instructor presenting the lecture attended the class - the instructors were not coresident in class. In developing the IPD course, however, we realized that the each of our areas of expertise (business and engineering) were so very different that we needed to better understand the other's material before we could sufficiently appreciate the interface issues involved, much less attempt to address questions competently. We decided from the beginning, therefore, that if we were going to teach integrated product development, it was important that we attend all lectures and labs, so that we could more effectively weave together the disciplines represented by each of us in the classroom. Since we are trying to teach about how an organization should conduct itself in an integrated manner, it would be very hypocritical should we proceed to present our materials in a traditional sequential, discipline-focused manner.

\section{Visiting Production Facilities}

In many engineering courses, we tour production facilities to acquaint students with the physical aspects of product design and manufacturing, we invite individual speakers and panels to discuss various aspects of the product realization process during class lecture periods. While the IPD class does indeed visit a small number of production facilities, our objective has been identifying opportunities to examine the integrated product development team processes at the companies we visit. The students meet with members of IPD teams and discuss practitioners' views on what works and what is difficult about the IPD approach. This has been a rich 
adjunct to the students' overall understanding of the IPD process, and it appears to present information that would not be available in most of the literature available to the class today.

\section{Customer Involvement}

Since a customer focus in essential in new product development, contact with customers is a critical aspect of the student team projects. At the same time, the limited time frame of an academic quarter discourages extensive use of marketing research. We strike a balance by presenting alternative marketing research approaches ${ }^{7,8,9}$ and encouraging the student teams to tailor marketing research to the needs of their specific projects.

\section{Conclusions}

The Integrated Product Development course has been taught by the authors for three years. And while we have learned a great deal about the proper content and approach for teaching the material, we know there are still opportunities to increase the relevance of the material to the business community. Our larger challenge, however, is finding ways to engage companies in the IPD course so that students obtain a better understanding of the complex manner in which technologies, fundamental knowledge and organizational skills work in concert. It would be desirable to have more substantial industry involvement in the student projects, to introduce students to the product development needs of a real company, to provide access to customers and resources of the company, and to offer advice and insight throughout the project. The greatest value of industry involvement in student projects is the real-world perspective they bring to the projects.

We can expect that the increasing competitive pressures facing manufacturing organizations is a trend that will parallel an increasing globalization of markets and production resources. Shortening the time needed to bring the correct products to market will depend on the ability of the firm to effectively integrate all of its product realization resources. For many companies it will be difficult to change the environment of silos and functional domains in which the model for communications and coordination is defined by the hierarchical constraints of the organization chart. We believe that multi-disciplinary courses, such as the one discussed here, are an important means of preparing students for an increasingly competitive global economy in which the winners will be those able to combine the organizational skills and advanced technologies with a comprehensive understanding of customers and their needs.

\section{Bibliography}

1. Stalk, Jr., George and Thomas M. Hout, Competing Against Time, New York: The Free Press, 1990.

2. Bowen, H. Kent, Kim B. Clark, ,Charles A. Holloway and Steven C. Wheelwright (eds.), The Perpetual Enterprise Machine, New York: Oxford University Press, 1994.

3. Ulrich, Karl T. and Steven D. Eppinger, Product Design and Development, New York: McGraw-Hill, 1995.

4. Turino, John, “Making It Work Calls for Input From Everyone,” IEEE Spectrum, July, 1991, 30-32.

5. Corporate Design Foundation, "Teaching Collaborative Product Development," 1994 Program Report, Boston, Massachusetts: Corporate Design Foundation, 1994. 
6. Graedel, Thomas E. and Brad R. Allenby, Industrial Ecology, Englewood Cliffs, New Jersey: Prentice Hall, 1995.

7. Dolan, Robert J., Managing the New Product Development Process, Reading, Massachusetts: AddisonWesley Publishing Company, 1993.

8. Griffin, Abbie and John R. Hauser, “The Voice of the Customer,” Marketing Science, 12/1 (Winter), 1993, $1-27$.

9. Urban, Glen L. and John R. Hauser, Design and Marketing of New Products (Second Edition), Englewood Cliffs, New Jersey: Prentice Hall, 1993.

\section{Biographical Information}

JOSEPH A. HEIM. Dr. Heim is an assistant professor of Industrial Engineering at the University of Washington in Seattle, Washington. His primary teaching responsibilities include computer integrated manufacturing systems, simulation, inventory management and scheduling. Professor Heim is a member of ASEE.

GARY M. ERICKSON. Dr. Erickson is an associate professor of Marketing in the School of Business at the University of Washington in Seattle, Washington. His teaching centers on marketing management and strategy, and his research interests focus on quantitative modeling and the analysis of competitive strategies. Professor Erickson is an associate editor for Management Science. 